\title{
Violencias en el fútbol argentino: claves para pensar su deconstrucción
}

\author{
Juan Branz* \\ Nicolás Cabrera* \\ José Garriga Zucal ${ }^{* *+}$ \\ Verónica Moreira ${ }^{*+* *}$ \\ Diego Murzi ${ }^{* * * * *}$ \\ Sebastián Rosa ${ }^{*+*+* *}$ \\ Javier Szlifman
}

* Doctor en Comunicación y Licenciado en Comunicación Social por la Universidad Nacional de La Plata. Investigador Asistente del CONICET en el Instituto de Altos Estudios Sociales (IDAES) de la Universidad Nacional de San Martín (Argentina).

** Licenciado en Sociología por la Universidad Nacional de Villa María, y doctor en Antropología por la Universidad Nacional de Córdoba (Argentina). Becario posdoctoral del CONICET.

*** Licenciado en Antropología y doctor en Antropología social por la Universidad de Buenos Aires (UBA). Investigador independiente del CONICET.

**** Licenciada en Antropología y doctora en Ciencias Sociales por la Universidad de Buenos Aires (UBA). Investigadora Independiente del CONICET en el Instituto de Investigaciones Gino Germani (FSOC/UBA). Correo electrónico: veromoreira175@gmail.com

Licenciado en Sociología, y doctor en Ciencias Sociales por la Universidad de Buenos Aires (UBA).

${ }^{* * * * * *}$ Licenciado en Sociología por la Universidad Nacional de La Plata. Becario doctoral del CONICET en el Instituto de Investigaciones en Humanidades y Ciencias Sociales (IDIHCS).

${ }^{* *+\ldots+a * *}$ Licenciado en Ciencias de la Comunicación por la Universidad de Buenos Aires.

Equipo de Investigación del Proyecto PIP CONICET/Argentina: Violencia y medios de comunicación. La construcción de las representaciones legítimas sobre la violencia en el campo futbolístico.

Fecha de recepción: 19/04/2020. Fecha de aceptación: 02/10/2020. 


\title{
Violencias en el fútbol argentino: claves para pensar su deconstrucción
}

\section{RESUMEN}

Este artículo revisa una serie de planteos que realizamos en 2013 sobre los distintos factores que intervienen y condicionan el desarrollo de la violencia en el fútbol argentino. En dicho análisis incluimos un conjunto de propuestas tendientes al diálogo con el sector de las políticas públicas nacionales, con miras a generar una solución al problema. Hoy, el número de heridos y muertos asociados al hecho futbolístico continúa creciendo. Según datos publicados por la Asociación Civil Salvemos al Fútbol, 332 personas han muerto en Argentina en situaciones relacionadas con el fútbol. Nuestro estudio sobre el problema de "las violencias" (porque no existe un solo responsable ni una sola manera de expresar la violencia) involucra una multiplicidad de actores sociales de distintos espacios (barras, hinchas comunes, dirigentes, políticos, periodistas, fuerzas de seguridad, representantes del Poder Judicial) y diferentes factores (históricos, simbólicos, políticos, de seguridad, organizativos, periodísticos). Frente a un fenómeno tan complejo, que presenta distintas facetas y protagonistas, la respuesta nunca puede ser una súper ley, un megaoperativo, una hipersanción, detenciones en masa, prohibición de visitantes o derechos de admisión. La solución nunca puede ser la mirada puramente judicializadora. Por esto, apuntamos a presentar algunas claves para (de)construir el hinchismo argentino.

Palabras clave: fútbol, violencias, factores, seguridad, propuesta.

\section{Violence in Argentine football: keys to thinking about his deconstruction}

\begin{abstract}
This article reviews a series of proposals that we made in 2013 about the different factors that intervene and condition the development of violence in Argentine football. In this analysis we include a set of proposals aimed at dialogue with the national public policy with the intention of generating a solution to this problem. Until today, the number of wounded and dead associated with football continues to grow. According to data published by the ONG Salvemos Al Fútbol, 324 people have died in Argentina in situations related to football. Our study on the problem of «violences» (because there is no one single responsible or a single way of expressing violence) involves a multiplicity of social actors from different areas (hooligans, common fans, leaders, politicians, journalists, security forces, representatives of the judiciary) and different factors (historical, symbolic, political, security, organizational, journalistic). Faced with such a complex phenomenon, which presents different facets and protagonists, the answer can never be a super-law, a mega-operation, a hyper-sanction, mass arrests, prohibition of visitor fans or admission right execution. The solution can never be a purely judicialized look. For this reason, we aim to present some keys to deconstruct Argentine supporters.
\end{abstract}

Keywords: football, violences, factors, security, proposal. 


\section{INTRODUCCIÓN}

En este trabajo proponemos un diagnóstico y un conjunto de líneas de acción para pensar el fenómeno de la violencia en el fútbol argentino, a partir de la revisión y el análisis de un texto que varios de nosotros publicamos en $2013^{1}$. La escritura nos lleva de modo directo a la comparación entre la primera propuesta, que diseńamos considerando distintas dimensiones que habían sido investigadas hasta aquel momento, y las producciones más recientes de jóvenes investigadores que confirman algunos de los aspectos sugeridos inicialmente y renuevan la mirada sobre otros.

¿Qué cambios se dieron en torno al problema de la violencia en el fútbol argentino en los últimos años? ¿Cuál es el cuadro de situación actual? ¿Qué aristas se incorporaron en las perspectivas académicas? ¿Qué medidas estatales se elaboraron para comprender, contener, prevenir y solucionar los hechos violentos y los factores que hacen posible su desarrollo? ¿Cuáles son los aportes de las ciencias sociales? Un hecho que no ha cambiado en absoluto es el de las muertes sucedidas en contextos futbolísticos. Por el contrario, la lista de fallecidos ha aumentado durante estos años de manera exponencial. En el texto de 2013, señalamos el registro de 261 víctimas. En las puertas del 2020, según datos publicados por la Asociación Civil Salvemos al Fútbol —considerando al fútbol de Primera y al de Ascenso, a las ligas profesionales tanto como a las regionales - 332 personas han fallecido en Argentina en situaciones relacionadas con eventos futbolísticos desde 1922 (primer deceso registrado $)^{2}$. Asimismo, un hecho sobresaliente ha marcado la historia reciente del espectáculo futbolístico argentino: la muerte televisada de un hincha del club Atlético Belgrano de Córdoba en un estadio en 2017, en plena vigencia de la última medida estatal para enfrentar el problema: la prohibición del público visitante. Resulta relevante destacar que durante la última década se registraron 87 muertes, lo que equivale a decir que casi nueve hinchas murieron por año en este período.

Los datos muestran la permanencia del tema no solo en las ciencias sociales sino también en el campo de las políticas públicas estatales, las cuales no han modificado su línea de interpretación durante estos años (Alabarces, 2014; Cabrera et al., 2016; Murzi, 2019). En términos generales, estas se basaron exclusivamente en la multiplicación y sofisticación de sistemas de vigilancia y represión. Las políticas públicas asumen que los hinchas son sospechosos, peligrosos, y que deben ser controlados (Sustas, 2013). Para esto, se aumentaron paulatinamente las cantidades de policías

\footnotetext{
«Diagnóstico y propuestas para la construcción de una seguridad deportiva en Argentina» (Pablo Alabarces, Diana Ávila, Juan Branz, Ramón Burgos, Nicolás Cabrera, Federico Czesli, Rodrigo Daskal, José Garriga Zucal, Alcira Martínez, Diego Murzi, Juan Manuel Sodo, Sebastián Sustas y Javier Szlifman), Impetus, 7(1), 59-65

2 Ver http://www.salvemosalfutbol.org/listavictimas.htm.
} 
involucrados en los «operativos» ${ }^{3}$, al mismo tiempo que se desarrollaron dispositivos de identificación para extremar la vigilancia, y se propusieron numerosos proyectos de ingresos biométricos (AFA-Plus, Fan-id, Pasaporte del hincha), que tuvieron su materialización en el programa Tribuna Segura actualmente vigente (Rosa, 2017; Murzi, 2019). Tribuna Segura consiste en un control de documentación de identidad previo al ingreso al estadio que se aplica sobre todos los espectadores. A su vez, la medida de mayor alcance y más significativa ha sido la prohibición del público visitante, que exacerba la lógica de la separación y refuerza la idea de la imposibilidad de convivencia entre hinchadas rivales como principal hipótesis de conflicto (Rosa, 2017). Esto se complementa con la persecución penal y judicialización de los actores considerados peligrosos. A partir del gobierno de Mauricio Macri (20152019) se incorporó además la búsqueda por visibilizar resultados, exhibiendo cantidad de personas sancionadas, en un intento por mostrar una supuesta productividad y eficiencia que no se vio traducida en la disminución de hechos violentos.

Otra institución (auto)investida de autoridad para tratar el problema es el periodismo deportivo que, salvando excepciones, incurre en constantes equivocaciones. El tratamiento, con frecuencia, resulta viciado por los respectivos intereses en juego, como por ejemplo alimentar el show o engordar el negocio de la seguridad (Alabarces, 2003). Ya en la manera misma de referirse a la cuestión hay un problema (Szlifman, 2010) que no es retórico sino ético, en la medida en que encierra supuestos erróneos: porque no hay «violentos» sino condiciones que posibilitan el acontecer de prácticas violentas en torno de eventos futbolísticos (Alabarces et al., 2012). Estas condiciones, al involucrar distintos planos y sectores, vienen a echar por tierra la consabida figura del «culpable». Nuestro argumento, menos espectacular que los habituales (una súper ley, un megaoperativo, una hipersanción, detenciones en masa, prohibición de públicos visitantes o derechos de admisión al estadio de los supuestos culpables), apunta a trabajar focalizando precisamente allí donde la mirada puramente judicializadora no alcanza: en las condiciones mismas de posibilidad de la práctica.

La tasa de fallecidos plantea con urgencia la participación activa de diferentes actores sociales: desde el Estado con sus órbitas y dependencias, organizaciones no gubernamentales y diversos grupos de la sociedad civil. En este sentido, en el ámbito académico, desde hace varios ańos, las y los investigadores dedicados a indagar dicho problema trabajamos para brindar nuestro aporte desde una perspectiva que pretende complejizar algunas de las respuestas posibles, intentando romper

\footnotetext{
3 En Argentina se denomina «operativos de seguridad» al despliegue organizado por las agencias estatales de seguridad alrededor de los estadios los días de partido. Ese «operativo» está comandado por las policías, que movilizan gran cantidad de agentes policiales para controlar a los espectadores.
} 
los límites que desde el campo jurídico (sobre todo) se cristalizaron a la hora de atender el escenario planteado. Desarmar analíticamente el escenario futbolístico argentino es uno de los caminos para solucionar las muertes en el fútbol: describirlo, entenderlo, analizarlo. Esa es la propuesta de este artículo, además de formar redes de conocimiento sobre el fenómeno con agentes que exceden el campo académico intelectual.

Quienes elaboramos este diagnóstico y propuestas sostenemos prácticas de investigación científica en el marco de universidades públicas y organismos del Estado como el CONICET. Esas investigaciones han producido conocimiento novedoso - volcado en artículos, foros, tesis doctorales y libros- sobre algunos de los sectores implicados en el tema que nos convoca: grupos de hinchas, medios de comunicación, organismos de seguridad, entre otros. La metodología implementada en nuestros trabajos ha sido, por un lado, la etnografía con sus dos técnicas principales, la observación participante y la entrevista en profundidad, y, por otro lado, el análisis y la crítica cultural en torno a las representaciones de los medios de comunicación sobre los hechos de violencia. Las etnografías se realizaron en diferentes períodos durante los últimos veinte años: con los hinchas que integran las llamadas «barras bravas» de los clubes Independiente, Colegiales, Huracán, Belgrano, Platense, en sus respectivos barrios, espacios de socialización y sociabilidad, tanto en la provincia de Buenos Aires como en la Ciudad Autónoma de Buenos Aires. La misma metodología se implementó para observar los operativos de seguridad durante diferentes eventos futbolísticos. El análisis de los medios de comunicación ha sido un trabajo que hemos llevado a cabo durante los últimos dos años en el marco de un proyecto de investigación financiado por el CONICET ${ }^{4}$.

\section{DimenSIONES}

En nuestro análisis consideramos una serie de factores que hacen a las condiciones de posibilidad de aparición de la violencia en el fútbol. Estos han sido —y siguen siendo- abordados en detalle en nuestros respectivos trabajos de investigación.

El primero de esos factores es el componente histórico, vinculado con la lógica que se fue construyendo en Argentina durante la apropiación de la práctica del fútbol inglés. En la Argentina el fútbol, desde su misma génesis, otorgó preponderancia a la búsqueda y exhibición de triunfos a cualquier precio, asociando el logro

\footnotetext{
4 Proyecto PIP CONICET «Violencia y medios de comunicación. La construcción de las representaciones legítimas sobre la violencia en el campo futbolístico", dirigido por la doctora Verónica Moreira y codirigido por el doctor+ José Garriga Zucal, con asiento en el Instituto de Investigaciones Gino Germani, Facultad de Ciencias Sociales de la Universidad de Buenos Aires.
} 
deportivo con el honor, la masculinidad y la identidad barrial-territorial y homologando rival con enemigo (Alabarces, 2003; Frydenberg, 2011). Dicho de otra manera: en nuestro país el fútbol es el producto de un pasaje gradual de una ética del juego como una cuestión de caballeros (fair play) a una ética del juego como una práctica donde el objetivo es triunfar (Archetti, 1985). Esta práctica quedó asociada de manera temprana a una noción de masculinidad donde los machos conocen los códigos y no lloran si el rival, apelando a artimañas, les saca ventaja deportiva. Esto va a suponer algunas resultantes. Por un lado, que desde entonces el fútbol argentino admitirá la posibilidad de la sospecha y eso, en sí, ya genera un clima hostil y paranoico de antemano, casi como regla. A la par, como se trata de una cosa de hombres, no queda otra que aguantársela. Y ahí tenemos una primera versión de lo que, sobre todo a partir de la década de 1990 , se conoce como el aguante 5 .

El segundo factor tiene que ver con la organización institucional del fútbol argentino. La organización ha conjugado constantes irregularidades arbitrales y organizativas en los campeonatos: programación de horarios de partidos, criterios de sanción disímiles según el club, entre otras: irregularidades que abonan el aludido histórico clima de sospecha y rompen con el contrato básico sobre el que se asienta todo deporte moderno: la igualdad de condiciones y la meritocracia. Las declaraciones de dirigentes, jugadores, técnicos, medios de comunicación y hasta dirigentes políticos que ponen en duda la honestidad y la imparcialidad de los árbitros y asociaciones (AFA, CONMEBOL) atentan contra la credibilidad de los organismos. En ese marco, el fin del gobierno de Julio Grondona al frente de la AFA a partir de su fallecimiento en 2014 no implicó mayor transparencia. En estos años postgrondonistas, encontramos al menos dos grandes casos que pusieron en tela de juicio la integridad y la capacidad de la dirigencia nacional. Por un lado, el propio Grondona, junto a los empresarios argentinos vinculados con la AFA Alejandro Burzaco, Hugo y Mariano Jinkins, fueron juzgados por tribunales estadounidenses en el marco de las denuncias de corrupción contra los principales dirigentes de la FIFA que implicaron la suspensión de su presidente Joseph Blatter en 2015. Por otro lado, las elecciones internas de la AFA del 3 de diciembre de 2015 dejaron la imagen televisada de la sorpresa de los dirigentes ante una paridad en 38 votos cada candidato sobre los 75 votantes, un cálculo tan imposible como irregular, que terminó con la intervención de la asociación por el gobierno nacional. Estos casos, entre otros, socavan la credibilidad y legitimidad de la dirigencia del fútbol mundial

\footnotetext{
5 Aguante es uno de los términos nativos más relevantes para comprender las lógicas de las violencias en el fútbol argentino (ver Alabarces, 2004). En estas páginas mencionaremos las «lógicas del aguante» para dar cuenta de las formas en que las barras significan sus prácticas violentas. Las palabras en cursiva corresponden a los términos nativos expresados en los contextos en los que llevamos a cabo las investigaciones.
} 
en general y argentino en particular, incrementando la sospecha de intervención de factores que modifican la igualdad de condiciones.

Encontramos un tercer factor, de tipo simbólico, referido a valoraciones propias de los sectores intervinientes en la situación problemática, en al menos cinco planos:

1) El plano de la lógica de bandos con la que hinchas y policías se perciben mutuamente. Para unos, la policía no es percibida como el Estado en la calle sino como una hinchada más, la más fuerte, la de uniforme. Para la policía, por su parte, los hinchas no serían tanto ciudadanos a proteger como amenazas a combatir (Galvani y Palma, 2005).

2) El plano de las implicancias de la cultura del honor que soporta y rige el accionar de las barras. Como comunidad, estas evalúan la conducta de sus miembros refiriéndola a patrones de conducta ideal. Según las conductas se acerquen o se alejen de dicho ideal, oscilan entre la acumulación de prestigio o la vergüenza. ¿Cómo se acumula honor? En las últimas tres décadas, la forma de incrementar este valor ha sido a través de la obtención de banderas de los equipos rivales (llamadas trofeos de guerra), de peleas contra hinchas de otros clubes (participando de combates) y de la invasión del territorio ajeno (caminando en el barrio del otro). Caer en un estado de humillación conlleva a la recuperación de la imagen honorable por medio de las acciones señaladas. Así, la consecuencia es una interminable secuencia de reparaciones del honor mancillado (Moreira, 2005).

3) El plano de las implicancias de la puesta en juego del capital simbólico-violencia, ese que los integrantes de las barras deben constantemente efectuar y exhibir para insertarse en redes de prestigio, sociabilidad, dones, contradones e intercambios (comerciales, laborales, asistenciales, de favores, de lealtades, etc.). Aparte de una práctica que los distingue y diferencia, y que les brinda un nosotros de pertenencia en el que compartirla — nosotros, que a su vez les genera protección y vínculos de solidaridad-, el ser reconocido como poseedor del capital-violencia otorga a su detentador admiración e idolatría en la cancha de parte del resto de los espectadores y reputación en el barrio (Garriga Zucal, 2007).

4) El plano de la identidad de género que se dirime en el ritual futbolero y sus implicancias. Porque en un partido de fútbol no se juega únicamente la gloria deportiva del club y los futbolistas. Simultáneamente está en juego la condición sexual de los hinchas varones (Archetti, 1985). Esta dimensión encuentra su máxima expresión en los cánticos de cancha cuya función es la degradación de la posición de los rivales futbolísticos por medio del uso de metáforas de su sometimiento sexual. Las imágenes de penetración anal y sexo oral son comunes en los estadios. La discusión actual en torno a este punto es si esto confirma 
la homofobia del fútbol argentino o es una manifestación del folklore nacional (Bundio, 2018). En el contexto actual de avance del movimiento de mujeres y los feminismos, los valores constituyentes del fútbol argentino basados en un tipo de masculinidad que jerarquiza la fuerza, la potencia, la destrucción y eliminación del otro comienzan a ser discutidos en distintas esferas, por ejemplo: en los medios de comunicación, en la academia y en los mismos clubes de fútbol. Algunas instituciones deportivas han desarrollado capacitaciones y talleres con el objetivo de concientizar sobre la violencia de género a raíz de una serie de episodios de este tenor protagonizados por jugadores.

5) El plano de un ritual como el futbolístico argentino en el que, a diferencia de otros tipos de rituales, predominan los componentes dramáticos por sobre los carnavalescos (Archetti, 1985). En línea de continuidad con el punto anterior, el drama se experimenta a diario con cantos plagados de imágenes de conflicto, guerra y destrucción. Sin duda, las consignas, lemas y cantos tendientes a alentar y arengar al equipo han sido elementos centrales de la historia del fútbol argentino. No obstante, la faceta trágica del espectáculo predomina de maneras distintas, no solo en los cantos en los que la eliminación del otro es un tópico constante, sino también en los muertos reales que en Argentina producen una tasa de homicidios que no se corresponde de manera directa con la estadística de homicidios de la sociedad en general.

El cuarto factor, que podemos denominar "político», está vinculado a que caudillos partidarios, punteros barriales, funcionarios policiales, actores gubernamentales, dirigentes deportivos, jefes sindicales o empresarios tienen una relación de reciprocidad e intercambio para con las barras. En rigor, las relaciones entre algunos de estos actores no pueden tratarse solo desde el paradigma de la utilidad material, a partir de la idea de toma y daca, sino que deben comprenderse como relaciones personalizadas atravesadas por el afecto, la lealtad, la fidelidad y la amistad. Lejos de pensar en relaciones construidas a partir de un intercambio descarnado de favores (votos por dinero, ayudas por bienes materiales), deben interpretarse en muchos casos como partes de una trama de vínculos familiares y cercanos (Moreira, 2012). De ahí que sea tan complejo comprender y desentrañar el fenómeno de la violencia en el fútbol.

El quinto factor que identificamos está vinculado con la gestión de la seguridad. Partimos de la idea de que para prevenir hay que conocer. Y para conocer es indispensable reponer la voz del hincha, sus puntos de vista, los valores que subyacen a sus acciones. De lo contrario, y si se lo considera de antemano como un irracional, "la violencia» aparece como lo impensable. De ese modo, se supondrá al evento futbolístico como intrínsecamente peligroso. Este es el supuesto sobre el que se asientan en nuestro país los «operativos de seguridad» organizados por las agencias 
de seguridad deportiva y las policías (Garriga et al., 2020). La seguridad en los estadios se ha pergeñado históricamente a partir de las hipótesis de conflicto. En consecuencia, se trabaja con acciones de vallado, alambrado, tabicado, escoltamiento, separación de los ingresos por calles, desconcentración de las parcialidades a distintos tiempos, prohibición de asistencia al público visitante... todo en pos de evitar el encuentro de los cuerpos. En relación con ello, sostenemos, reponiendo la vieja premisa del Informe Taylor inglés, que «si se trata a los hinchas como animales, es de esperar que se comporten como animales».

En segundo lugar, distintos trabajos sociológicos han encontrado que este supuesto es el mismo de un paradigma de seguridad que en la Ciudad de Buenos Aires atañe no solo al fútbol, sino también al espacio público en lo que a plazas y parques concierne. Otros estudios muestran que, en Córdoba, por ejemplo, la mayoría de los socios del club Atlético Belgrano de Córdoba define a la policía como uno de los principales actores causantes de la violencia, al mismo tiempo que clasifica a los ingresos y egresos a los estadios como los momentos más violentos durante un día de partido (Cabrera, Morales y Plaza Schaefer, 2019). Por último, hay que decir que el esfuerzo por policializar estadios es, además de prejuicioso, obsoleto. ¿Por qué? Porque, como arrojan las estadísticas, buena parte de las actuales muertes o incidentes están teniendo lugar entre hinchas del mismo equipo. Es decir, entre cuerpos que se encuentran del mismo lado de la reja. Y no solamente eso, sino que, además, una de cada tres muertes está teniendo lugar fuera del estadio e incluso durante la semana ${ }^{6}$. Por último, una serie de incidentes registrados en partidos disputados a puertas cerradas también demuestran lo obsoleto de este paradigma.

El sexto factor es el de los estadios, que se halla en estrecha relación con el punto anterior, constituyendo un doble factor de posibilidad para el acontecer de prácticas violentas. Por un lado, los sanitarios en malas condiciones, el hacinamiento (en la tribuna, en el ingreso o en el egreso), la mala iluminación, los pasillos y bocas de acceso imposibles, todo contribuye a la percepción de maltrato. Por otro, los estadios constituyen un factor crucial en tanto el hincha, íntimamente, sabe que, en caso de urgencia (derrumbe, incendio, avalancha, descompostura), la cancha puede convertirse en una trampa mortal, lo cual no puede sino predisponer agresivamente a las personas.

En séptima instancia identificamos el rol del periodismo deportivo como factor que crea las condiciones para la existencia de prácticas violentas. En el marco de la economía política del sistema de medios, sus presentaciones suelen ser fragmentadas y estereotipadas de los hechos, que reproducen prejuicios y sentidos comunes que se instalan como dominantes. Ejemplos de todo ello:

6 Ver http://www.salvemosalfutbol.org/investigaciones.htm 
1) La abundancia de afirmaciones irresponsables — siempre proclives a los giros bélicos—, la cizaña, la polémica y las retóricas dramáticas para mantener, más con los criterios del show que con los del relato, la tensión en épocas de sobreabundancia de oferta informativa.

2) Las transmisiones televisivas de partidos en directo y el repaso repetitivo de resúmenes y compactos que, amparados por el desarrollo tecnológico, capaz de detenerse una y mil veces a verificar al milímetro y desde decenas de cámaras lo que el árbitro tiene que resolver en tiempo real, están todo el tiempo remarcando los fallos arbitrales y poniendo así en duda su imparcialidad, contribuyendo de paso a crear una manera judicial de ver fútbol.

3) Los discursos periodísticos que tienden a vincular frecuentemente el problema de la violencia con las barras bravas, presentando a estos grupos como los únicos culpables de los hechos, mientras se ocultan otras formas y prácticas violentas de otros actores, como hinchas, periodistas, jugadores, dirigentes y políticos.

4) Los discursos masivos que tienden a presentar las prácticas violentas como producto de seres irracionales, con metáforas vinculadas con la animalización de los sujetos, clausurando cualquier posibilidad de interpretación y comprensión sobre este tipo de acciones. Lejos de ello, las prácticas violentas son racionales y con un sentido propio para los actores. Basta ver el tratamiento mediático del caso Balbo para ejemplificar lo dicho ${ }^{7}$.

5) Asistimos a la emergencia de la lógica del periodismo que, fundamentalmente, en entrevistas o conferencias de prensa (pre o pos partido) se configura de la siguiente manera: el o la periodista que pregunta al jugador o entrenador se hace eco de las supuestas palabras que otro jugador o entrenador rival ha dicho sobre la figura entrevistada (siempre con una connotación negativa). Esto produce en el interpelado una inmediata respuesta —indirecta - al supuesto enunciador de algún agravio. Esto constituye una lógica de lo que, en tendencia, los periodistas llaman «tener el título». Significa recortar uno, dos o tres enunciados que revisten una función emotiva-polémica, para presentar al público especializado luego en portales web o en medios tradicionales. Hacemos hincapié en este tipo de prácticas porque son tendencia en la construcción de la noticia futbolística: «contestar a un periodista lo que otro dijo sobre mí, sin que yo lo haya escuchado». Esto nutre una posterior trama de "chimentos» ${ }^{8}$ sobre lo

\footnotetext{
7 https://www.youtube.com/watch?v=iQupXjUJVR4

8 La categoría "chimento» forma parte de un argot utilizado, mayoritariamente, en zonas ubicadas en América del Sur. La forma lingüística alude a una cadena discursiva (diferenciada de ciertos tonos y modos de conversación coloquiales) emparentada con la adjetivación negativa de ciertas personas y situaciones sucedidas en determinados momentos y espacios. El «chimento", para la cultura sudamericana, forma parte de lo no dicho públicamente (o masivamente) siempre en detrimento de terceros
} 
dicho y lo no dicho, de manera indirecta, siendo los periodistas y los soportes en donde construyen la noticia el puente hacia los públicos que, de manera especializada, conforman una usina de conocimiento especializado basada en el chisme, la degradación del otro, y la polémica como factor central del espectáculo.

6) Un tipo de cobertura como la del diario deportivo Olé, que fomenta una manera autorreferencial de ser hincha, más pendiente muchas veces de la performance de la hinchada que del equipo. Este modelo reproduce discursos de los fanáticos y da lugar a un despliegue de muchos de los recursos mencionados en los puntos precedentes, como afirmaciones dramáticas, visiones indignadas y metáforas bélicas.

7) Actualmente, los derechos televisivos han sido privatizados y las transmisiones de los partidos están a cargo de señales privadas. Esto reduce el acceso de los públicos al espectáculo futbolístico televisivo, generando, en el campo de las televidencias, una circulación poco democrática y menos plural. Las alternativas para los públicos excluidos (ya excluidos de los estadios, ahora del acceso a las transmisiones) pueden ser los sitios web denominados "piratas» o ilegales para ver los partidos cada fecha. Esto no es menor: la restricción al derecho a la información y el entretenimiento es cercenado, marcando la integración o expulsión de televidentes.

Finalmente, identificamos el factor «hincha común», hincha así bautizado por el sentido común mediático-futbolero, quien es parte del mapa de condiciones de posibilidad en, al menos, tres sentidos?.

1) Si tomamos al "hinchismo» como un discurso —esto es, como una máquina de hablar y escuchar que atraviesa a todos los y las hinchas del fútbol argentino por igual-, tenemos que decir que dicha máquina les provee procedimientos y mecanismos discursivos que, lejos de favorecer el registro del problema y su implicación en la elaboración de este, lo fomentan, obstaculizan e invisibilizan (Sodo, 2012).

\footnotetext{
que no participan de la charla. Desde la década de 1990 (del siglo XX), el chimento fue traducido al lenguaje televisivo, vertebrando horas y horas al aire y consolidando un subgénero que estableció un contrato de alta filiación con públicos masivos.

9 En términos generales, la barra refiere a los grupos organizados de hinchas que hacen de la violencia física un signo de su identidad. En este caso, la violencia es deseada, buscada y celebrada, porque permite capitalizar el aguante, categoría nativa que concentra valores fundamentales como la valentía, el coraje, la hombría, el valor, el honor. Por otra parte, una característica de la barra es la relación directa con un sector de la dirigencia del club de pertenencia. El término «barra brava» se usa comúnmente para señalar a este tipo de grupo desde una mirada ajena y estigmatizante. En este texto, usamos hincha o hincha común para señalar a las personas que no integran estos grupos organizados. Para comprender en profundidad la diferencia entre hinchas y barras, ver Alabarces, 2004.
} 
2) El hincha "posaguante» celebra y legitima, cuando no directamente festeja, la bravura de su barra, que combate contra hinchas rivales y que centraliza la organización de cantos y el despliegue de banderas en las tribunas del estadio. Este tipo de hincha no solo celebra y legitima, sino que además filma y fotografía con celulares los hechos protagonizados por los integrantes de la barra para luego colgar tales producciones en distintos sitios de la web (YouTube, blogs y sitios partidarios, cuentas de Facebook), con miras a ganar un torneo imaginario por la posesión del aguante. Pero también puede suceder que este tipo de hincha se sienta obligado a cantar lo que canta la barra y no pueda boicotearla, por ejemplo, mudándose de tribuna, insultando o directamente no yendo a la cancha en caso de estar en desacuerdo con algún comportamiento de esta, del equipo o de la dirigencia del club.

3) Este mismo hincha común —en este caso, independientemente de la lógica del aguante, ya que se trata, como dijimos, de un rasgo histórico- muchas veces reclama de su barra aprietes y protección, casi como si esta fuera un brazo armado, una fuerza de choque o un autor material. Aprietes (amenazas verbales o físicas) contra jugadores propios, a los árbitros, a futbolistas e hinchas visitantes; protección, por su parte, en lo que atañe a cuidar las instalaciones del club cuando los visitantes lo están dañando, o en lo concerniente a la defensa personal ante situaciones de peligro cuando viajan de visitantes a otros estadios.

Luego de esta enumeración, podemos sostener que lo sorpresivo en Argentina no es que «haya violencia» en el fútbol, sino el hecho de que no haya aún más.

El acontecer de prácticas violentas en torno de eventos futbolísticos no es algo «irracional», «ilógico», «sinsentido» y «accidental», producto de «anormales», «inadaptados» al ritual del fútbol, como pretenden periodistas y organismos de seguridad (anormalidad que, no hace falta decirlo, recae siempre en los barras pero jamás en los demás grupos de hinchas comunes, socios, trabajadores de clase media que, como se desprende de nuestros argumentos, participan generando condiciones para el accionar y la legitimación de aquellos) ${ }^{10}$. Por el contrario, se trata de algo que responde

\footnotetext{
10 No está de más reiterarlo: al opinar, la prensa no hace sino caer en compendios de lugares comunes estigmatizantes. Los resultados de un estudio recuperan las maneras en que puntualmente la prensa gráfica analiza y nombra a los hinchas aparentemente responsables en incidentes ocurridos entre 1967 y 1997. Allí los autores del trabajo agrupan las denominaciones en tres grandes conjuntos de metáforas y series. Por un lado, la metáfora y la serie "criminal-bélica», a la que corresponden términos tales como "grupos patoteros», "patota» (caso Souto: Clarín, Crónica, La Nación, 1967), «delincuentes organizados», «asesinos», «organizaciones mafiosas», «bandas delictivas» (caso VallejosDelgado, Crónica, 1994), "grupo de choque», "guerrilla» (caso Souto, Clarín, 1967), «mercenarios» (caso Vallejos-Delgado, Crónica, 1994). Por otro, la metáfora y la serie «animal-infrahumana», a la que corresponden, además del clásico «inadaptados», términos como «salvajes», «bárbaros», «bestias», «energúmenos», «monstruos». Finalmente, aunque en menor medida, la serie y la metáfora
} 
a racionalidades y lógicas muy concretas, ancladas en valoraciones relevantes para los sectores implicados, según los cuales, por ejemplo, las prácticas violentas en el contexto del fútbol no solo son permitidas, sino además consideradas legítimas (aunque luego, ante las cámaras y los micrófonos, casi todos busquen desentenderse).

\section{Preguntas y desafíos para Pensar la seguridad deportiva}

Una meta que nos hemos propuesto es la de intervenir en el debate público sobre los pormenores del problema de la violencia en el fútbol. Desde hace varios años, discutimos y reflexionamos sobre este tema. Como producto de esos encuentros y los intercambios realizados durante este tiempo, hemos elaborado una serie de premisas generales, sostenidas simultáneamente en supuestos que debemos seguir testeando y poniendo a prueba en nuestros análisis. Nuestra mirada es ajustable y adaptable a los casos particulares (seguramente no son lo mismo clubes de ciudades con una estructuración dicotómica de las rivalidades que aquellos que se encuentran en las zonas difusas que se despliegan entre la Capital Federal y el Conurbano Bonaerense).

Siguiendo las etnografías realizadas en el ámbito del fútbol, una primera impresión es que, en materia de seguridad, los y las hinchas son protagonistas. En el día a día, nadie conoce los secretos del ir y el estar en la cancha como ellos o ellas. Y nadie se vería más damnificado por la desaparición de lo que experimentan y defienden como una fiesta. Entonces, ¿por qué no diseñar canales institucionales de diálogo y consulta con el fin de otorgarles injerencia en las decisiones? ¿Por qué no abrir espacios donde constituirlos como interlocutores e interlocutoras calificados al momento de, por ejemplo, diseñar la seguridad de un partido de fútbol e incluso, por qué no, sancionar una nueva ley de espectáculos deportivos que mejore a la vigente, más inspirada en el Estatuto do torcedor que en el Código Penal? ¿Por qué no hacer que se sientan respaldados, escuchados y tenidos en cuenta?

Por lo general, las acciones desplegadas por los operativos de seguridad o las medidas elaboradas son vividas como normativas externas y prohibitivas, $y$, en consecuencia, como una invitación a la transgresión. Dicho de otra manera: nadie cuida aquello de lo que no se siente parte. Por el contrario, los y las hinchas comunes, incluidos en el debate, podrían autorregular sus prácticas y comportamientos y podrían terminar autogestionando la seguridad en los estadios. Ellos y ellas, ocupados en gestionar los asuntos comunes de la cancha y de la fiesta, se desinteresarían

\footnotetext{
«biologicista», tan familiar al discurso militar: «cáncer», «tumor», «virus», que vendrían a ser extirpados por los «anticuerpos de la sociedad» (caso Vallejos-Delgado, La Nación, 1994). En definitiva: a diferencia de lo que nuestro mapa deja en evidencia, aquí en cualquiera de los casos se trata de diagnosticar una anormalidad — un sinsentido, algo inexplicable - y proponer su eliminación (ver Coelho et al., 1998).
} 
de cualquier iniciativa violenta. $Y$ esto no significa inocencia o una actitud naif: no suponemos un hincha ideal.

La institución policial hoy en día participa activamente de las disputas por la masculinidad, el honor y el aguante. A su vez, sostiene vínculos necesarios para el mantenimiento de mercados ilegales en relación con dirigentes y barras bravas (Garriga Zucal, Murzi y Rosa, 2017). Su accionar está guiado por la actuación represiva, siendo parte de lo que los hinchas perciben como un problema y múltiples maltratos. En ese marco, la portación de armas, de por sí violenta, estigmatiza al público como eminentemente sospechoso y lo judicializa. Como contrajemplo, podemos ver otros espectáculos masivos en los que la policía solo actúa ante situaciones de delitos y se mantiene en el exterior de los estadios. Proponemos, por lo tanto, formar una fuerza estatal de agentes de seguridad desarmados y especialmente entrenados y capacitados para actuar en espectáculos futbolísticos, asistiendo en primer lugar a la resolución de conflictos. A su vez, priorizamos el gobierno civil de la seguridad, apuntando a una dirección de los operativos guiada por los principios del respeto de los derechos de todas las personas involucradas en los espectáculos futbolísticos, con participación activa de hinchas y de especialistas en la gestión de la seguridad y la comunicación.

Por otra parte, criminalizar a las barras ha sido tan inútil como contraproducente. Sus violencias se mantienen al paso que sus mercados ilícitos se expanden. Las barras están institucionalizadas de hecho en todos los clubes del fútbol argentino. Proponemos institucionalizarlas de derecho. Crear una figura legal que permita regular sus actividades económicas, como así también identificar responsables jurídicos por su accionar. Pero nada de lo dicho funcionaría si, paralelamente, no llevamos adelante un trabajo social de carácter inclusivo y preventivo con estos grupos. Debemos modificar aquel paradigma que solo las reconoce desde la represión legal y la estigmatización social, para proponer canales de diálogo que permitan consensos multiactorales en pos de una convivencia democrática e inclusiva en todos los estadios de nuestro país. Reconocemos que es una tarea difícil, pero estamos convencidos de que, a partir de nuestras investigaciones científicas sobre barras más las experiencias internacionales de similar enfoque que también estudiamos (Brasil, Colombia, Bélgica, Alemania), podemos proponer un tratamiento de la "cuestión barra» alternativo a lo que ya se evidenció como un fracaso rotundo (Segura Trejo y Murzi, 2013).

Un aspecto para ser reconocido en este debate es el rol de las hinchadas en general y las barras en particular como espacios de inclusión y grupalidad, en el marco de una sociedad donde los lazos históricos de sociabilidad se han debilitado. Las agrupaciones de hinchas han jugado un papel en el entramado social. Se hace más evidente el lugar relevante que deben cumplir en ese aspecto los clubes sociales 
- y especialmente el Estado_ - en su reconocimiento y su institucionalización. Esto no impide que los delitos que puedan cometer barras o hinchas en general sean sancionados y tratados por la justicia. Pero esta no puede ser la principal y menos la única forma de vincularnos con la problemática, porque no se estaría actuando en términos de prevención, sino de castigo posterior a los hechos.

Sobre el modo y las gramáticas con que se tratan y debaten públicamente temas en el actual sistema de medios, no se puede hacer mucho. No obstante, sería menos imposible intervenir sobre sus contenidos. Resulta interesante en este sentido la creación de un observatorio que module términos discriminatorios, retóricas dramatizantes, enunciados irresponsables y sancione alusiones a hechos que, durante las transmisiones, no tengan que ver con el partido propiamente dicho.

¿Por qué no cambiar el foco? ¿Por qué no pasar de controlar el grupo minoritario (barras) a enfocar la prioridad en la mayoría de los asistentes al estadio? Esto es: que se sientan protegidos, que sientan que tienen voz y voto en las decisiones, y derechos como hinchas, a partir de la apertura de canales de diálogo y representación con las autoridades de los clubes y la AFA. Si la constante retórica "hay que hacer como los ingleses» fuera consistente, se vería que esta fue la principal lógica de la reforma británica: organizar un fútbol para los espectadores, y no para una mínima porción involucrada en actos violentos; el paso de la security a la safety (Alabarces, 2004). Pero, además, iniciar un proceso de deconstrucción de su hinchismo para superar la ya conocida afirmación de la lógica del aguante (que sobrevalora un tipo de masculinidad), rescatando los elementos festivos y carnavalescos por sobre los dramáticos que sostienen las disputas violentas por el honor.

\section{Conclusiones}

Algunas de las acciones que surgen del análisis del fenómeno de la violencia en el fútbol se encuentran a continuación.

A través de campañas, capacitaciones y jornadas se puede intervenir sobre la lógica del aguante que hoy está presente en todos los estadios, generando las condiciones para hacer consciente la legitimidad que actualmente presenta. Ejemplo: trabajar con una campaña que demuestre en qué dimensión todos los actores hacemos del fútbol un espacio donde las prácticas violentas son aceptadas. Solo formamos parte de las soluciones cuando nos asumimos como parte del problema. Esto mismo se puede articular con los espacios de género que en la actualidad se están organizando y constituyendo en algunas instituciones deportivas para discutir las desigualdades que sufren a diario las mujeres y las personas del colectivo LGBTQ+ en diferentes planos, como atletas (la discusión sobre la participación de las mujeres trans en deportes femeninos está vigente), dirigentas, socias, médicas, entrenadoras, 
kinesiólogas, periodistas. El movimiento de mujeres y los feminismos han avanzado de manera contundente en diferentes ámbitos, y el deporte no ha sido un espacio de excepción. Este proceso está ayudando a deconstruir los modos del hinchismo argentino que se destacan por tener como horizonte la defensa de un prototipo de masculinidad que se ha consolidado con el correr de las décadas. Reconocer que este modelo tiene un origen cultural es un avance, pues este no tiene nada de natural, aunque los valores que lo conforman se encuentren fuertemente naturalizados.

Múltiples actores participan de la lógica del aguante. Por este motivo, la capacitación no está orientada únicamente a los y las hinchas, sino también a los dirigentes, jugadores y técnicos para que ellos mismos (en sus acciones públicas, decisiones y declaraciones en los medios) no sean reproductores de las violencias que circulan y estructuran el fútbol argentino. Particularmente durante la formación profesional, pero también en otras instancias, resulta fundamental la capacitación en materia de violencia de género y masculinidades, racismo, sexismo, homofobia, xenofobia, transfobia y todas las declaraciones y prácticas de odio y discriminación.

En los últimos años se han institucionalizado algunos espacios llamados Subcomisiones de los hinchas en el ámbito de los clubes, que dan el marco para que los y las hinchas preparen la fiesta de la popular. Un desafío es capitalizar estos espacios para gestionar los valores de la lógica del aguante en sentidos que resulten más productivos. La articulación con los espacios de género que son llamados de distintos modos según el grado de institucionalización y operatividad en los clubes (área de género, secretaría, subcomisión, etc.) es un recorrido para transitar. Precisamente, una crítica que socias e hinchas han realizado públicamente contra el hinchismo argentino se basa en la entonación de cantos (todo un clásico en nuestro país) que legitiman las violencias enunciadas anteriormente.

En términos de la seguridad en los estadios, se presentan varios factores para tener en cuenta. En primer lugar, considerar la formación de un gobierno civil, con operativos y gestión de la seguridad a cargo de organismos con participación de hinchas, dirigentes, especialistas en seguridad y en comunicación. En segundo lugar, crear un "Estatuto de los y las hinchas» en el que se establezcan, de manera consensuada entre los sectores (grupos de hinchas, dirigentes, organismos de seguridad, organismos de control), las obligaciones y los derechos de los y las hinchas, se regule la utilización de pirotecnia, el uso de banderas, etc. En tercer lugar, formar una agencia estatal de trabajadores de seguridad especialmente entrenados y capacitados para la actuación en espectáculos deportivos que no utilice armas letales y que sea encargada de la seguridad en los estadios. Reforzar y retomar las experiencias de Control de Admisión y Permanencia, incorporando actores a la gestión no policial de la seguridad. En cuarto lugar, capacitar fuerzas de seguridad para acciones de prevención en espectáculos masivos. Que la tarea policial esté centrada en actuar 
solo en caso de ser llamada a intervenir por la agencia no policial de la seguridad, o ante situaciones delictivas que pongan en riesgo la integridad o la vida de los hinchas; por ejemplo, planificación e implementación de operativos o evacuación de estadios en caso de accidente.

Un desafío es volver a permitir la participación del público visitante en los estadios, como ha sucedido en casos particulares durante el último año. El primer párrafo de este artículo da cuenta del incremento de muertes ocurridas en la última década y que la única muerte televisada (la de Emanuel Balbo) se dio en un estadio solo con público local. Esto demuestra que la medida de prohibición del público visitante no tuvo un sentido de prevención. En la misma línea, podría buscarse paulatinamente la formación de pulmones de convivencia en los que participan hinchas de ambos equipos en determinados sectores.

Otro tipo de medidas que proponemos es analizar y regular las páginas web, los sitios partidarios y todos los medios en los que se incite a prácticas violentas. Implementar una política homogénea de acción y sanción en todo el país para terminar con las decisiones incoherentes que hoy son tomadas por distintos organismos provinciales o por comisarios jurisdiccionales que hacen de la zona en la que se encuentra el estadio un feudo. Tornar claras y justas las sanciones a las instituciones por hechos de violencia, y no ser tolerantes según el peso político de cada club. Mejorar drásticamente las condiciones edilicias, de higiene y seguridad de los estadios (sobre todo los de las categorías de ascenso): sanitarios, bocas de acceso y egreso, salidas de emergencia, iluminación, calidez, estética en general, pues estas condiciones muchas veces favorecen la producción de acciones violentas.

Estas propuestas, tentativas y esquemáticas, y que admiten mucho más desarrollo en la práctica cotidiana, tienen dos presupuestos. El primero: nunca han sido utilizadas, por lo que cuentan con la enorme ventaja de su novedad, frente al fracaso sistemático y mensurable en víctimas de la judicialización y la policialización aún vigentes. El segundo: están basadas en el conocimiento riguroso y novedoso, validado por instituciones científicas nacionales e internacionales, que hemos construido a lo largo de más de una década. Sobre él, diseñamos estas propuestas y líneas de acción. Hemos difundido todo ese material con papers, artículos y libros, pero también con divulgación e intervención periodística en columnas de opinión, entrevistas gráficas, radiales y televisivas, páginas web, paneles, mesas redondas o debates públicos. Estamos peor que hace veinte años, cuando comenzamos este periplo, porque, independientemente de las pequeñas satisfacciones de nuestro trabajo, como el apoyo de nuestros colegas y nuestros estudiantes, no solo no hemos convencido, sino que hemos seguido registrando muertos, heridos, daños e incidentes. No hemos salvado una sola vida, y aunque tamaña pretensión puede sonar excesiva para cientistas sociales, seguimos convencidos de que nuestro trabajo tiene 
sentido únicamente en la posibilidad de, como decía Marx, no solo interpretar el mundo, sino transformarlo. Cuando la ausencia de esa transformación significa la continuidad de muertes sistemáticamente jóvenes e injustas — como cada muerte previsible y evitable-, no podemos evitar el regusto del fracaso.

Y la necesidad de redoblar el esfuerzo, claro: esa es la dimensión necesaria de nuestra testarudez. Estas propuestas quieren ser la dimensión urgente de nuestra intervención pública.

\section{REFERENCIAS}

Alabarces, P. (2003). El fútbol y las identidades. Prólogo a los estudios latinoamericanos. En P. Alabarces (comp.), Futbologias: Futbol, identidad y violencia en América Latina. Buenos Aires: CLACSO.

Alabarces, P. (2004). Crónicas del aguante. Fútbol, violencia y política. Buenos Aires: Capital Intelectual, Colección Claves para todos.

Alabarces, P. (2014). Héroes, machos y patriotas. El fútbol entre la violencia y los medios. Buenos Aires: Aguilar.

Alabarces, P., Garriga Zucal, J. y Moreira, M. V. (2012). La cultura como campo de batalla. Fútbol y violencia en la Argentina. Estudios de Comunicación y Política, (29), 10-10.

Alabarces, P., Ávila, D., Branz, J., Burgos, R., Cabrera, N., Czesli, F., ..., Szlifman, J. (2013). Diagnóstico y propuestas para la construcción de una seguridad deportiva en Argentina). Ímpetus, 7(1), 59-65. https://doi.org/10.22579/20114680.64

Archetti, E. (1985). Fútbol y ethos. Monografias e Informes de Investigación, 7, Buenos Aires: FLACSO.

Bundio, J. (2018). La construcción del otro en el fútbol. Identidad y alteridad en los cantos de las hinchadas argentinas, Cuadernos de Antropología Social, 2018, 195-212. https://doi.org/10.34096/cas.i47.3733

Cabrera, N., Morales, S. y Plaza Shaefer, V. (2019). Seguridad y violencia en el fútbol. La experiencia de un abordaje preventivo en el club Atlético Belgrano (Córdoba, Argentina). En A. Amaya y S. Tafur (eds.). Fútbol y politicas públicas: miradas desde América Latina. Cali: Universidad Nacional de Cali.

Cabrera, N., Czesli, F. y Garriga, J. (2016). El aguante en debate: violencia en el fútbol y políticas públicas en la Argentina. Esporte e Sociedade, 11(27).

Coelho, R., Lobos, A., Sanguinetti, J. y Srabsteni, Á. (1998). Del lugar común al estigma. La cobertura de la violencia en el fútbol en la prensa argentina. Ponencia ante las IV Jornadas de Investigadores de la Cultura. Buenos Aires: Instituto Gino Germani, Facultad de Ciencias Sociales.

Frydenberg, J. (2011). Historia social del fútbol; del amateurismo a la profesionalización. Buenos Aires: Siglo XXI.

Galvani, M. y Palma, J. (2005). La hinchada de uniforme. En P. Alabarces y otros, Hinchadas. Buenos Aires: Prometeo. 
Garriga Zucal, J. (2007). Haciendo amigos a las piñas. Violencia y redes sociales de una hinchada. Buenos Aires: Prometeo.

Garriga Zucal, J., Murzi, D. y Rosa, S. G. (2017). Enemigos intimos. Recuperado de http:// www.revistaanfibia.com/ensayo/enemigos-intimos/

Garriga Zucal, J., Murzi, D. y Rosa, S. (2020). El triple pacto. Del gobierno de la seguridad a la regulación de la violencia en el fútbol argentino. En J. Garriga Zucal y L. Panizio (eds.), Sufrir, matar y morir. Contribuciones a la socio-antropología de las violencias y las muertes. Buenos Aires: Teseo.

Moreira, M. V. (2012). Juego Electoral y relaciones políticas en el fútbol argentino. História: Questóes \& Debates, (57), 127-149. https://doi.org/10.5380/his.v57i2.30577

Moreira, M. V. (2005). Trofeos de guerra y hombres de honor. En P. Alabarces y otros, Hinchadas. Buenos Aires: Prometeo.

Murzi, D. (2019). Fútbol, violencia y Estado. Un estudio sobre las políticas públicas de seguridad deportiva en Argentina (2006-2017) [tesis de doctorado inédita]. Buenos Aires: Facultad de Ciencias Sociales, Universidad de Buenos Aires.

Rosa, S. G. (2017). La década sin visitantes. Un análisis de los discursos sobre la prohibición del público visitante en el fútbol argentino [tesis de licenciatura en Sociología]. Buenos Aires: Facultad de Humanidades y Ciencias de la Educación, Universidad Nacional de La Plata.

Segura Trejo, F. y Murzi, D. (2013). Alternativas europeas comparadas de gestión de la seguridad y la violencia en los estadios de fútbol: tres enfoques y aplicaciones diferentes. ¿Qué se puede aprender? En J. Garriga Zucal (comp.), Violencia en el fútbol. Investigaciones sociales y fracasos politicos. Buenos Aires: Godot.

Sodo, J. M. (2012). Prácticas de sociabilidad en un grupo de hinchas del fútbol argentino y sus vinculaciones con la producción de ambientes de violencia en torno del espectáculo futbolístico [tesis doctoral, Doctorado en Comunicación Social]. Rosario: Facultad de Ciencias Políticas y RR. II., Universidad Nacional de Rosario.

Szlifman, J. (2010). La fiesta que no fue. Un análisis sobre los medios de comunicación y la violencia en el fútbol argentino [tesis de grado en Ciencias de la Comunicación]. Buenos Aires: Facultad de Ciencias Sociales, Universidad de Buenos Aires.

Sustas, S. E. (2013). Las violencias sentenciadas. Análisis de las leyes en torno a la seguridad deportiva en Argentina. En Violencia en el fútbol. Investigaciones sociales y fracasos políticos. Buenos Aires: Godot. 